\title{
PENGETAHUAN KADER TENTANG SISTEM 5 MEJA DI POSYANDU WILAYAH KERJA PUSKESMAS JATINANGOR KABUPATEN SUMEDANG
}

\author{
Didah $^{1}$ \\ 1Departemen IImu Kesehatan Masyarakat Fakultas Kedokteran Universitas Padjadjaran. \\ Email : didahramdani@gmail.com
}

\begin{abstract}
Background posyandu or Integrated Service Post is one of UKBM that has been highly developed in Indonesia. The existence of the Posyandu is to facilitate the public in getting health services. Cadre has important role $n$ implementing posyandu. Cadres have a role in posyandu activities, for example to be a driving force for the 5-table system at Posyandu, but in reality the 5-table system has not been running optimally, it can be influenced by several factors, one of them is knowledge.

The purpose of this research is to find out the cadre's knowledge about the 5 tables system in posyandu. This research is descriptive with cross-sectional approach. The sample in this study was cadres in the working area of Jatinangor Health Center.

Methode sampling using Propotionate Stratified random sampling technique with a sample size of 83 respondents.

The research instrument uses a questionnaire that has been tested for validity and reliability. Research shows 51 respondents (61.4\%) with good knowledge, 26 respondents (31.3\%) with enough knowledge, and 6 respondents $(7.2 \%)$ with less knowledge. district is good.

The conclusion knowledge of cadres in the posyandu at the Jatinangor health center in Sumedang posyandu activities.
\end{abstract}

Keywords: Cadre, Posyandu, 5 table system

\section{ABSTRAK}

Latar Belakang Posyandu atau Pos Pelayanan Terpadu merupakan salah satu UKBM yang sudah sangat berkembang di Indonesia. Keberadaan Posyandu tersebut yaitu untuk memudahkan masyarakat dalam mendapatkan pelayanan kesehatan. Dalam penyelenggaraan posyandu yang memiliki peran penting salah satunya adalah kader. Kader memiliki peran dalam kegiatan Posyandu salah satunya yaitu menjadi penggerak sistem 5 meja di Posyandu, Namun pada kenyataannya sistem 5 meja belum berjalan secara optimal hal tersebut dapat dipengaruhi oleh beberapa faktor salah satunya pengetahuan.

Tujuan dari penelitian ini yaitu untuk mengetahui gambaran pengetahuan kader tentang sistem 5 meja di posyandu. Penelitian ini adalah Deskriptif dengan pendekatan cross-sectional. Sampel dalam penelitian ini adalah kader di wilayah keja Puskesmas Jatinangor.

Metode pengambilan sampel menggunakan Teknik Propotionate Stratified random sampling dengan jumlah sampel 83 responden.Instrumen penelitian menggunakan kuesioner yang telah diuji validitas dan reliabilitas.

Hasil menunjukan 51 responden (61.4\%) dengan pengetahuan baik, 26 responden (31.3\%) dengan pengetahuan cukup, dan 6 responden (7.2\%) dengan pengetahuan kurang.

Simpulan pengetahuan kader di posyandu wilayah kerja puskesmas Jatinangor kabupaten sumedang baik.

Saran bagi kader posyandu agar pengetahuan nya tentang system 5 meja di aplikasikan dengan baik pada saat kegiatan posyandu.

Kata Kunci: Kader, Posyandu, Sistem 5 meja 


\section{PENDAHULUAN}

Posyandu atau Pos Pelayanan Terpadu merupakan salah satu UKBM yang sudah sangat berkembang di Indonesia. Posyandu adalah kegiatan berbasis masyarakat untuk layanan kesehatan di Indonesia. Keberadaan Posyandu tersebut yaitu untuk memudahkan masyarakat dalam mendapatkan pelayanan kesehatan. Kementerian Kesehatan menyebutkan terdapat 289.635 Posyandu di Indonesia pada tahun 2014. Data Riset kesehatan Dasar Tahun 2013 terdapat 49.193 Posyandu di Jawa Barat dan sebanyak 1.567 Posyandu terdapat di kabupaten Sumedang. Posyandu yang aktif sebanyak 770 dari seluruh Posyandu yang ada di kabupaten Sumedang. Posyandu terselenggara karena dukungan dari semua pihak.

Penyelenggara posyandu yang memiliki peran penting salah satunya adalah kader.Kader merupakan bagian dari masyarakat itu sendiri yang sukarela bersedia, mampu, dan memiliki waktu untuk melaksanakan kegiatan Posyandu sehingga kader sangat memengaruhi berjalannya kegiatan Posyandu itu sendiri. Adapun beberapa karakteristik kader yang memengaruhi peran dan fungsi kader di Posyandu yaitu umur, tingkat pendidikan, tingkat pengetahuan, pelatihan kader, jarak dari rumah ke Posyandu, dukungan suami atau keluarga, status pernikahan, pekerjaan, lamanya menjadi kader, dan penghasilan.

Berdasarkan penelitan tentang evaluasi program 5 meja pada posyandu balita mengatakan bahwa sistem 5 meja di posyandu belum semuanya berjalan secara optimal sejalan dengan penelitian bahwa pada pelayanan Meja 1 sampai Meja 3 $(100 \%)$ melakukan kegiatan dengan kategori baik sedangkan pada Meja 4 (26.7\%) yang melakukan kegiatan sehingga secara keseluruhan Meja 4 dikategorikan tidak baik. Penelitian ini sejalan dengan penelitian yang dilakukan oleh Suryani di Puskesmas Silih Nara Kabupaten Aceh Tengah tahun 2012, menemukan bahwa dalam pelaksanaannya penyuluhan sewajarnya dilakukan setiap selesai dilakukan penimbangan, namun pada kenyataannya banyak petugas atau kader tidak melakukannya. Dalam Penelitian yang dilakukan oleh Tri Sunarsih pada Meja 5 pun hanya (33.3\%) yang melakukan kegiatan sehingga secara keseluruhan Meja 5 dikategorikan tidak baik. Mengingat pentingnya peran dan fungsi kader di posyandu serta dari beberapa kesenjangan penelitian tentang karakteristik kader, peneliti tertarik untuk mengetahui gambaran pengetahuan kader posyandu di wilayah kerja puskesmas jatinangor kabupaten sumedang tentang 5 meja di Posyandu.

\section{METODE PENELITIAN}

Jenis penelitiani yang digunakan adalah Deskriptif dengan rancangan penelitian crosssectional. Sumber data yang digunakan adalah data primer yang diperoleh dari hasil kuisoner. Populasi dalam penelitain ini adalah semua kader di posyandu wilayah kerja Puskesmas Jatinangor kabupaten Sumedang sebanyak 83 kader. Sampel diambil dengan cara Propotionate Stratified random sampling. Instrumen Penelitian ini menggunakan kuesioner yang sudah di uji validitas dan reliabilitas. Dalam pengolahan data, setelah data dari kuesioner terkumpul akan direkapitulasi dan di hitung menggunakan rumus penghitungan:

Rumus yang digunakan adalah:

$$
\mathrm{N}=\frac{S P}{S M} \times 100 \%
$$

Keterangan:

$N$ : Nilai pengetahuan

$S P$ : Skor yang didapat

$S M$ : skor tertinggi maksimum

Dalam prosentase tersebut kemudian dikonversikan dalam kategori kualitatif, sebagai berikut:

1. Pengetahuan baik, skor: $\geq 80 \%$

2. Pengetahuan cukup, skor: $60-80 \%$

3. Pengetahuan kurang skor $<60 \%$

\section{HASIL DAN PEMBAHASAN \\ Tabel 1 Distribusi Frekuensi Pengetahuan Responden}

\begin{tabular}{|c|c|c|}
\hline Pengetahuan & $\mathrm{N}$ & $\%$ \\
\hline 1. Baik & 51 & 61.4 \\
\hline Cukup & 26 & 31.3 \\
\hline 3. Kurang & 6 & 7.2 \\
\hline Total & 83 & 100 \\
\hline
\end{tabular}

Menurut Skinner, seseorang dikatakan memiliki pengetahuan apabila seseorang tersebut mampu menjawab materi tertentu baik secara lisan maupun tulisan. Pengetahuan memengaruhi sikap seseorang, semakin banyak aspek positif yang diketahui makan akan menimbulkan sikap positif terhadap objek. Perilaku akan lebih langgeng bila didasari pengetahuan.

Kader posyandu pada saat melakukan peran dan fungsi nya pada saat hari $\mathrm{H}$ buka posyandu, salah satunya yaitu melakukan 
pelaksanaan posyandu adalah dengan sistem lima meja yang meliputi Meja I melayani pendaftaran dan pencatatan bayi, balita, ibu hamil, ibu menyusui, dan pasangan usia subur, Meja II melayani penimbangan berat badan, Meja III melayani pengisian KMS (Kartu Menuju Sehat) berdasarkan hasil penimbangan berat badan, Meja IV melayani informasi berat badan bayi atau balita naik atau tidak, ibu hamil dengan risiko tinggi, pasangan usia subur yang belum menjadi akseptor $K B$, penyuluhan kesehatan, dan pelayanan pemberian makanan tambahan, oralit, vitamin $A$, tablet zat besi, kondom, pil KB untuk kunjungan ulang dan Meja $\mathrm{V}$ melayani pemberian imunisasi, pemeriksaan kehamilan, pemeriksaan kesehatan dan pengobatan, dan pelayanan KB IUD atau suntik.

Penelitian yang dilakukan Di Wilayah Kerja Puskesmas Mokoau Tahun 2017 mengenai peran kader Posyandu menyatakan bahwa peran kader sebelum dan setelah hari buka Posyandu jarang dilakukan bahkan tidak pernah, hanya peran saat hari buka Posyandu yang berjalan. Baik tidaknya peran kader tentu juga dilihat dari perannya pada hari buka Posyandu. Penelitian yang dilakukan di Desa Banyurejo Sleman Yogyakarta pada tahun 2012 mengatakan bahwa sistem 5 meja di posyandu belum semuanya berjalan secara optimal. Pelayanan pada Meja 1 sampai Meja 3 (100\%) yang melakukan kegiatan dengan kategori baik sedangkan pada Meja 4 (26.7\%) yang melakukan kegiatan sehingga secara keseluruhan Meja 4 dikategorikan tidak baik. Kemudian pada Meja 5 hanya $(33.3 \%)$ yang melakukan kegiatan sehingga secara keseluruhan Meja 5 dikategorikan tidak baik.

Berdasarkan Tabel 1 hasil penelitian peneliti di wilayah kerja puskesmas Jatinagor Kabupaten Sumedang, bahwa hasil pengetahuan kader tentang sistem 5 meja sebagian besar pengetahuannya baik yaitu sebesar $61,4 \%$.

\section{KESIMPULAN}

Berdasarkan hasil penelitian ini tingkat pengetahuan kader tentang sistem 5 meja di wilayah kerja Puskesmas Jatinangor Kabupaten Sumedang $61.4 \%$ baik, hal ini dikarena kan keaktifan kader dalam mengikuti refreshing kader.

\section{SARAN}

Saran bagi kader posyandu agar pengetahuan nya tentang system 5 meja di aplikasikan dengan baik pada saat kegiatan posyandu.

\section{DAFTAR PUSTAKA}

Azizah Nur Rohim SZ, Yuli Kusumawati. Perbedaan Pengetahuan Pada Remaja Putri Setelah Diberi PendidikanDengan Metode Ceramah Tanpa Media Dan Ceramah Dengan Media Buku Cerita. Jurnal Kesehatan.2016;1

Budiman, Rianto A. Kapita Selekta Kuesioner Pengetahuan dan Sikap dalam Penelitian Kesehatan. Jakarta: Salemba Medika; 2013

Djuahaeni, H., S. Gondodiputro, dan R. Suparman. Motivasi Kader Meningkatkan Keberhasilan Kegiatan Posyandu di Kabupaten Kuningan Jawa Barat. MKB, vol. 42, no. 4, hh. 140-14; 2010

Hidayat TS, Jahari, AB. Perilaku Pemanfaatan Posyandu HubungannyaDengan Status Gizi Dan Morbjditas Balitabul. Penelit. Kesehat. 2012;40(1):1-10

Kemenkes RI. Petunjuk Teknis Penyelenggaraan Posyandu Remaja. Jakarta:Kementerian Kesehatan RI. 2018

Kemenkes RI. Profil kesehatan indonesia 2014. Jakarta: Kementerian Kesehatan RI. 2015

Legi, Nonce L.Faktor yang berhubungan dengan keaktifan kader posyandu di wilayah kerja puskesmas ranotana weru.Volume 7 No. 2 November; 2015

Nazri Cut, Yamazaki Chico, Kameo Satomi, Herawati Dewi, Sekarwana Nanan, Raksanagara Ardini,et al. Factors Influencing Mother's Participation in Posyandu for Improving Nutritional Status of Children Under-Five in Aceh Utara District, Aceh Province, Indonesia BMC Public Health. 2016;16:69:1-9.

Putra, Gede Tamblang Baswara. Gambaran pengetahuan dan kinerja kader Posyandu di wilayah kerja upt Puskesmas Mengwi kabupaten Badung. E-JURNAL MEDIKA, VOL. 5 NO.10, OKTOBER, 2016

Suhat. Faktor-faktor yang berhubungan dengan keaktifan kader dalam kegiatan Posyandu (studi di Puskesmas Palasari kabupaten Subang ). Jurnal Kesehatan Masyarakat. 2014 Juli; 10 (1): 73 - 79

Sodarsono. Hubungan Motivasi dan Pendidikan Kader Dengan Kinerja kader Posyandu di Wilayah Kerja Puskesmas Talun kabupaten Blitar; 2010

Sunarsih, Tri. Evaluasi Program 5 Meja pada Posyandu balita di Desa Banyurejo Sleman. Yogyakarta: 2012 
Suryani. Gambaran kegiatan posyandu dan status gizi balita di wilayah kerja Puskesmas Silih Nara Kabupaten Aceh Tengah tahun 2012; 2012.

Tumbelaka Patricia, Limato Ralacia, Nasir Sudirman, Syafruddin Din, Ormel Hermen, Ahmed Rukhsana. Analisys of Indonesia's
Community Health Volunteers (kader) as Maternal Health Promoters in the Community Integrated Health Service (Posyandu) Following Health Promotion Training. International Journal of Community Medicine and Public Health. 2018:5(3):856-63. 